\begin{tabular}{lcl}
\hline Bentham OPEN & Open Medicine Journal \\
CrossMark & Content list available at: www.benthamopen.com/MEDJ/ \\
\hline
\end{tabular}

RESEARCH ARTICLE

\title{
Factors Predicting Glycemic Control in Type 1 Diabetic Patient
}

\author{
Meriem Yazidi*, Mélika Chihaoui, Fatma Chaker, Ons Rjeb and Hédia Slimane \\ Université de Tunis El Manar, Faculté de Médecine de Tunis, "La Rabta" Hospital, Endocrinology department, 1007 \\ Tunis, Tunisia
}

Received: August 28, 2015

Revised: July 31, 2016

Accepted: August 3, 2016

\begin{abstract}
:
Background:

Recent years have been marked by numerous advances in the quality of type 1 diabetes care. However, glycemic control remains suboptimal for many patients with type 1 diabetes. The aim of our study was to identify factors associated with poor glycemic control in type 1 diabetic patients.
\end{abstract}

\section{Methods:}

We studied in a retrospective manner, 188 type 1 diabetic patients, admitted to our department then followed up for at least one year.

Results:

There was a negative correlation between age at diabetes onset and HbA1c value ( $\mathrm{p}=0.02)$. Adolescents had higher HbA1c value than adults $(10.8 \pm 2.9 \%$ vs. $9.2 \pm 2.8 \%, \mathrm{p}=0.02)$. No relationship was found between number of daily insulin injections and mean HbA1c value. Mean HbA1c was higher in patients with poor compliance to insulin therapy $(11.1 \pm 3.3 \% v s .8 .9 \pm 2.4 \%, \mathrm{p}<0.0001)$, in those with less than 3 clinic visits per year $(10.7 \pm 3.5 \%$ vs. $9.0 \pm 2.1 \%, \mathrm{p}=0.001)$, in subjects with lipohypertrophy $(10.9 \pm 2.5 \%$ vs. $9.2 \pm 3.4 \%$, $\mathrm{p}=0.008)$ and those with known celiac disease $(14.5 \pm 5.2 \%$ vs. $9.6 \pm 2.9 \%, \mathrm{p}=0.005)$.

\section{Conclusion:}

Several factors were associated with poor glycemic control in our type 1 diabetic patients. Most of them can be changed in particular by strengthening education strategies.

Keywords: Education, Glycemic control, HbA1c, Insulin treatment, Type 1 diabetes.

\section{INTRODUCTION}

The Diabetes Control and Complication Trial (DCCT) and the follow-up study Epidemiology of Diabetes Interventions and Complications (EDIC) clearly showed that good glycemic control over a prolonged period delays the onset and slows the progression of microvascular and macrovascular complications in type 1 diabetic patients [1 - 3]. Recent years have been marked by numerous advances in the quality of type 1 diabetes care including more physiologic insulins, continuous subcutaneous insulin pump therapy, sophisticated blood glucose monitoring and newer education strategies. Nevertheless, glycemic control remains suboptimal for many patients with type 1 diabetes even in developed countries [4 - 7]. The present study aims to identify factors associated with poor glycemic control in Tunisian type 1 diabetic patients.

\footnotetext{
* Address correspondence to this author at the Endocrinology Department "La Rabta" Hospital Tunis, Tunisia; Tel: + 21698266061 ; E-mail: meriemyazidi@gmail.com
} 


\section{MATERIALS AND METHODS}

We undertook a retrospective study involving 188 type 1 diabetic patients admitted to the Endocrinology Diabetology department of the university hospital "La Rabta" between January 1999 and December 2004 and followed up for at least one year. The duration of the study was five years.

Patients with an unclear type of diabetes and pregnant women with type 1 diabetes were excluded.

Data were collected by medical records review regarding:

- Patient's age

- Patient's gender

- Diabetes duration

- Diseases associated with diabetes

- Insulin therapy: insulin regimen, number of daily injections, insulin dose, type of insulin

- Insulin therapy adherence: compliance behaviors assessed by the clinician at the time of health care visit. Poor compliance to insulin therapy was defined by intentional reduction in insulin dosage or omission of insulin injections.

- Frequency of clinic visits: number of clinic visits per year

- Practice of self-monitoring

- Presence of lipohypertrophy

- HbA1c at each clinic visit was recorded and used as an index of glycemic control.

HbA1c was measured by high-performance liquid chromatography (HPLC) method.

The study was approved by our hospital ethics committee.

Statistical Analysis was performed using SPSS version 13.0. We assessed HbA1c levels according to patients' demographic and clinical characteristics using the Student's t test for continuous variables and $\chi 2$ (chi-square) test for categorical data. Pearson's Correlation Coefficient was used to analyze relationships between HbA1c and other quantitative variables. Data were expressed as mean \pm standard deviation (SD). Statistical significance was posted at level $\mathrm{p}<0.05$.

\section{RESULTS}

Mean age of patients was 28.0 \pm 12.2 years (ranges: 1-77 years). They were 102 males and 86 females. One hundred and thirty patients (69.1\%) were adults (aged between 20 and 65 years) and $55(29.2 \%)$ were adolescents (aged between 13 and 19 years). The mean age at diagnosis of type 1 diabetes was $25.9 \pm 12.5$ years (ranges: 1-77 years). One hundred and thirty two patients $(70.2 \%)$ had newly diagnosed diabetes and $56(29.8 \%)$ had previously diagnosed diabetes with a mean duration of 7.0 \pm 6.2 years. The mean duration of follow-up was 3.6 \pm 1.5 years (ranges: 1-5 years).

Mean HbAlc value during the overall follow-up period was $9.7 \pm 3 \%$. There was a significant negative correlation between age at diabetes onset and mean HbA1c value $(\mathrm{p}=0.02)$. Adolescents had significantly higher HbA1c values than adults $(10.8 \pm 2.9 \%$ vs. $9.2 \pm 2.8 \%, \mathrm{p}=0.02)$ (Table $\mathbf{1})$.

Table 1. Mean HbA1c during follow-up in adults and adolescents.

\begin{tabular}{|c|c|c|c|}
\hline Follow-up year & Adolescents & Adults & $\boldsymbol{p}$ \\
\hline First year $(\mathrm{n}=99)$ & $9.1 \pm 2.3(\mathrm{n}=26)$ & $7.4 \pm 2.1(\mathrm{n}=73)$ & $\mathbf{0 . 0 0 1}$ \\
\hline Second year $(\mathrm{n}=97)$ & $10.8 \pm 3.8(\mathrm{n}=30)$ & $8.9 \pm 2.2(\mathrm{n}=67)$ & $\mathbf{0 . 0 1}$ \\
\hline Third year $(\mathrm{n}=82)$ & $11.4 \pm 3.4(\mathrm{n}=24)$ & $9.6 \pm 3.2(\mathrm{n}=58)$ & $\mathbf{0 . 0 2}$ \\
\hline Fourth year $(\mathrm{n}=72)$ & $11.0 \pm 3.5(\mathrm{n}=18)$ & $9.4 \pm 2.4(\mathrm{n}=54)$ & $\mathbf{0 . 0 2}$ \\
\hline Fifth year $(\mathrm{n}=77)$ & $10.7 \pm 3.2(\mathrm{n}=16)$ & $9.8 \pm 2.8(\mathrm{n}=61)$ & 0.29 \\
\hline
\end{tabular}

In the adolescent's group, there was numerical but no significant difference in the HbAlc value between boys and girls $(10.6 \pm 2.8 \%$ for boys $v s .11 .3 \pm 3.1 \%$ for girls, $\mathrm{p}=0.42)$.

Fig. (1) shows the course of mean HbA1c value during follow-up for patients newly diagnosed with diabetes $(\mathrm{n}=132)$. Mean HbA1c was $7.6 \pm 2 \%$ during the first year of follow-up, and increased significantly $(\mathrm{p}<0.0001)$ during the second year to reach a steady-state at $9.2 \pm 2.5 \%$. 


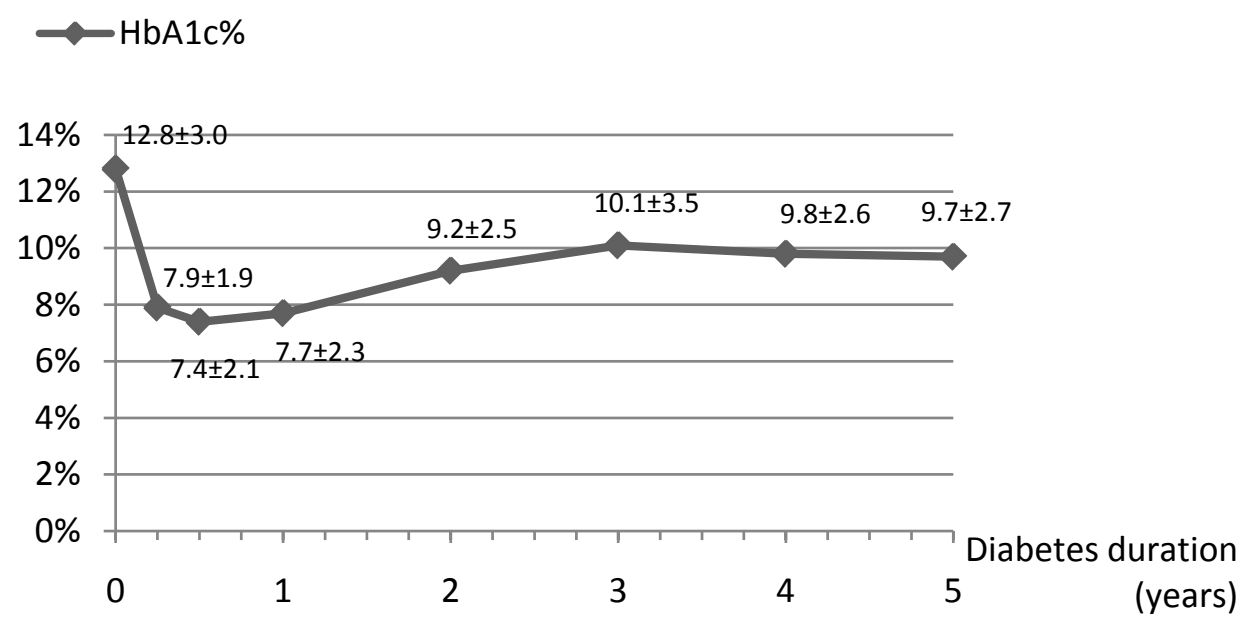

Fig. (1). Mean HbAlc value during follow-up for newly diagnosed patients.

The insulin treatment regimens initially prescribed included three injections a day in $75.6 \%$ of patients, two injections a day in $22.9 \%$ of patients and other insulin treatment regimens in $1.6 \%$ of patients. The percentage of patients on three daily insulin injections regimens became $58.9 \%$ at the end of the five-year study period. Compared to the group treated with twice daily injections regimens, patients on three daily injections regimens were younger and had an earlier onset of type 1 diabetes. No relationship between mean HbA1c value and the number of daily insulin injections was found during the follow-up period (Table 2).

Table 2. Patients' ages and mean HbA1c level at follow-up by insulin regimen.

\begin{tabular}{|c|c|c|c|}
\hline & $\begin{array}{c}\text { Three injection insulin regimen (n=142, } \\
\mathbf{7 5 . 6 \% )}\end{array}$ & Two injection insulin regimen (n=43, 22.9\%) & $\boldsymbol{p}$ \\
\hline Mean age (years) & $23 \pm 7.7$ & $39.4 \pm 12.1$ & $<\mathbf{0 . 0 0 0 1}$ \\
\hline Mean age at diabetes onset (years) & $21.7 \pm 8.2$ & $36.3 \pm 13.6$ & $<\mathbf{0 . 0 0 0 1}$ \\
\hline Mean HbA1c at follow-up (\%) & $9.6 \pm 2.2$ & $9.33 \pm 2.2$ & 0.53 \\
\hline
\end{tabular}

Poor adherence to insulin treatment, a number of clinic visits less than three per year, lipohypertrophy and celiac disease were associated with higher HbA1c levels. Poor adherence to insulin therapy was more frequent in adolescent patients (49.1\% of adolescents $v s .33 .6 \%$ of adults, $\mathrm{p}=0.04)$. Patients who practiced self-monitoring (at any frequency) had lower mean HbA1c level than those not practicing it at all. However, the difference was not statistically significant (Table 3).

\section{DISCUSSION}

The overall glycemic control of our patients was poor, setting the majority of them at a high risk of diabetes complications. Several factors were significantly associated with this poor glycemic control. Age at clinical onset of type 1 diabetes is one of these factors. In fact, the young age at diagnosis was associated with higher HbA1c during follow-up. This may be explained by the fact that autoimmune $\beta$ cell destruction is faster and more intensive in patients with early-onset type 1 diabetes mellitus. The process is less aggressive in adults and remnant insulin secretion may facilitate a better metabolic control $[8-10]$.

The period of adolescence is associated with an almost unavoidable deterioration in glycemic control. Our adolescent patients had significantly higher mean HbA1c value compared with adult patients (1.65\% higher). This might be explained by an increase in insulin resistance secondary to the hormonal changes of puberty [11]. Furthermore, adolescence is characterized by psychological changes, changes in daily life activities and in eating habits. All this may lead to a poor compliance with treatment [12]. In fact, poor compliance with insulin treatment was more frequent in our adolescent patients. 
Table 3. Mean HbA1c according to adherence to insulin treatment, number of clinic visits per year, blood glucose monitoring, lipohypertrophy and celiac disease.

\begin{tabular}{|c|c|c|}
\hline & Mean HbA1c at follow-up (\%) & $p$ \\
\hline $\begin{array}{l}\text { Adherence to insulin treatment } \\
\text { Poor }(n=74,39.4 \%) \\
\text { Good }(n=114,60.6 \%)\end{array}$ & $\begin{array}{c}11.1 \pm 3.3 \\
8.9 \pm 2.4\end{array}$ & $<0.0001$ \\
\hline $\begin{array}{l}\text { Number of clinic visits per year } \\
<3(\mathrm{n}=92,49 \%) \\
\geqq 3(\mathrm{n}=96,51 \%) \\
\end{array}$ & $\begin{array}{c}10.5 \pm 3.6 \\
8.9 \pm 2.1\end{array}$ & 0.001 \\
\hline \begin{tabular}{|l} 
Blood glucose monitoring \\
Practiced $(\mathrm{n}=20,10.6 \%)$ \\
Not practiced $(\mathrm{n}=168,89.4 \%)$
\end{tabular} & $\begin{array}{l}9.0 \pm 2.4 \\
9.7 \pm 3.0\end{array}$ & 0.3 \\
\hline \begin{tabular}{|l} 
Lipohypertrophy \\
Objectified $(\mathrm{n}=59,31.4 \%)$ \\
Not objectified $(129,68.6 \%)$
\end{tabular} & $\begin{array}{c}10.9 \pm 2.5 \\
9.2 \pm 3.4\end{array}$ & 0.008 \\
\hline $\begin{array}{l}\text { Celiac disease } \\
\text { Associated to diabetes }(n=3,1.5 \%) \\
\text { Not associated to diabetes }(n=185,98.5 \%)\end{array}$ & $\begin{array}{c}14.5 \pm 5.2 \\
9.6 \pm 2.9\end{array}$ & 0.005 \\
\hline
\end{tabular}

Although boys had lower mean HbA1c than girls, the difference was not significant. Numerous studies had shown that girls with type 1 diabetes had a worse metabolic control than boys. Gender differences in metabolic control may be explained by a higher insulin resistance, a higher prevalence of eating disorders and insulin misuse for weight-control purpose in female adolescents with type 1 diabetes [11 - 13].

Glycemic control is also related to the duration of type 1 diabetes. The lowest HbAlc values were recorded during the first year of diabetes onset and increased significantly over the next years. This is a well-known phenomenon often referred to as the "honeymoon period". In fact, the residual beta cell function may deliver intrinsic insulin for months to years after diagnosis [12].

With regard to insulin treatment regimen, the Diabetes Control and Complication Trial (DCCT) clearly showed that intensive insulin therapy (three or more injections per day of insulin or continuous subcutaneous insulin infusion) gave better glycemic control than conventional insulin therapy (two injections per day of insulin) [1]. However, in our study we did not find such difference in mean $\mathrm{HbAlc}$ between patients treated with twice daily injections regimens and patients treated with three daily injections regimens. This may be explained by tighter follow-up, in the DCCT study, based on self-monitoring of blood glucose and phone call "visits" to better adjust insulin doses.

Our results clearly showed that a poor adherence to insulin treatment was a factor that contributes to poor glycemic control. This finding is consistent with previous studies $[11,14,15]$. Morris et al. demonstrated a direct association between failure to take insulin and poor glycemic control in a cohort of 89 type 1 diabetic patients. There was a significant inverse association between the "adherence index" and $\mathrm{HbAlc}(\mathrm{p}<0.001)$ [11].

We demonstrated that the mean number of clinic visits per year contributed to a better glycemic control. In fact, the mean $\mathrm{HbA1c}$ value was lower in subjects with at least 3 visits per year. Previous reports have shown that type 1 diabetic patients with more frequent clinic visits had better metabolic control [16, 17]. A study of Kaufman et al. showed a significant difference in the mean HbAlc levels between subjects with 1 to 2 visits $v s .3$ to 4 visits per year $(9.0 \pm 2.0 \%$ vs. $8.3 \pm 1.6 \%, \mathrm{p}<0,05)[16]$.

Self-monitoring of blood glucose is an essential component of the management of type 1 diabetes. Several studies have shown that a more frequent self-monitoring of blood glucose was associated with lower HbAlc levels [18, 19]. In our study, the mean $\mathrm{HbA1c}$ was lower in patients who practiced self-monitoring compared with those not practicing it at all, but the difference was not significant. This is probably due to the small number of patients practicing the selfmonitoring. In addition, we have no idea about the quality of this self-monitoring (number of blood glucose determinations, how the patients use the data to adjust food intake, exercise or insulin therapy...).

We have also confirmed findings from other studies reporting that lipohypertrophy was associated with poorer glycemic control [20 - 22]. In the study of Kordonouri et al., patients with lipohypertrophy had significantly higher HbA1c values $(\mathrm{p}<0.05)$ [20]. This complication can be avoided by repeated education of type 1 diabetic patients about adequate insulin injection technique and by encouraging the patient to make regular self examinations. Injection sites should also be examined by health care providers at each clinic visit. 
The prevalence of celiac disease in type 1 diabetic patients is higher than in the general population [23 - 26]. Previous studies, concerning the influence of celiac disease on metabolic control in type 1 diabetic patients are conflicting [23, 26 - 28]. In our study, patients with type 1 diabetes and a known celiac disease had poorer glycemic control. However, we are limited by the small sample size.

\section{CONCLUSION}

Several factors were shown to be associated with poor glycemic control in our type 1 diabetic patients. Although some of these factors are not modifiable, such as age at diabetes onset and diabetes duration; others such as insulin treatment regimen, adherence to insulin therapy, practice of self-monitoring, appearance of lipohypertrophy can be changed and must be targeted by intervention strategies to improve the prognosis of these patients. An intensive patient education remains the cornerstone of a successful treatment.

\section{CONFLICT OF INTEREST}

The authors confirm that this article content has no conflict of interest.

\section{ACKNOWLEDGEMENTS}

Declared none.

\section{REFERENCES}

[1] The effect of intensive treatment of diabetes on the development and progression of long-term complications in insulin-dependent diabetes mellitus. N Engl J Med 1993; 329(14): 977-86.

[http://dx.doi.org/10.1056/NEJM199309303291401] [PMID: 8366922]

[2] Epidemiology of Diabetes Interventions and Complications (EDIC). Design, implementation, and preliminary results of a long-term follow-up of the Diabetes Control and Complications Trial cohort. Diabetes Care 1999; 22(1): 99-111. [http://dx.doi.org/10.2337/diacare.22.1.99] [PMID: 10333910]

[3] Retinopathy and nephropathy in patients with type 1 diabetes four years after a trial of intensive therapy. N Engl J Med 2000; 342(6): 381-9. [http://dx.doi.org/10.1056/NEJM200002103420603] [PMID: 10666428]

[4] Valle T, Koivisto VA, Reunanen A, Kangas T, Rissanen A. Glycemic control in patients with diabetes in Finland. Diabetes Care 1999; 22(4): 575-9.

[http://dx.doi.org/10.2337/diacare.22.4.575] [PMID: 10189534]

[5] Eeg-Olofsson K, Cederholm J, Nilsson PM, Gudbjörnsdóttir S, Eliasson B. Glycemic and risk factor control in type 1 diabetes: results from 13,612 patients in a national diabetes register. Diabetes Care 2007; 30(3): 496-502.

[http://dx.doi.org/10.2337/dc06-1406] [PMID: 17327311]

[6] Scottish Study Group for the Care of the Young Diabetic. Factors influencing glycemic control in young people with type 1 diabetes in Scotland: a population-based study (DIABAUD2). Diabetes Care 2001; 24(2): 239-44. [http://dx.doi.org/10.2337/diacare.24.2.239] [PMID: 11213872]

[7] Saunders SA, Wallymahmed M, MacFarlane IA. Glycaemic control in a type 1 diabetes clinic for younger adults. QJM 2004; 97(9): 575-80. [http://dx.doi.org/10.1093/qjmed/hch098] [PMID: 15317926]

[8] Decochez K, Keymeulen B, Somers G, et al. Use of an islet cell antibody assay to identify type 1 diabetic patients with rapid decrease in Cpeptide levels after clinical onset. Diabetes Care 2000; 23(8): 1072-8. [http://dx.doi.org/10.2337/diacare.23.8.1072] [PMID: 10937500]

[9] Törn C, Landin-Olsson M, Lernmark A, et al. Prognostic factors for the course of $\beta$ cell function in autoimmune diabetes. J Clin Endocrinol Metab 2000; 85(12): 4619-23.

[PMID: 11134117]

[10] Pozzilli P, Visalli N, Buzzetti R, et al. Metabolic and immune parameters at clinical onset of insulin-dependent diabetes: a population-based study. IMDIAB Study Group. Immunotherapy Diabetes. Metabolism 1998; 47(10): 1205-10. [http://dx.doi.org/10.1016/S0026-0495(98)90324-9] [PMID: 9781622]

[11] Morris D, Boyle D, Mcmahon A, Greene A, Macdonald M, Newton R. Adherence to insulin treatment, glycemic control, and Ketoacidosis in insulin-dependent diabetes mellitus. Lancet 1997; 350: 1505-10. [http://dx.doi.org/10.1016/S0140-6736(97)06234-X] [PMID: 9388398]

[12] Dahl-Jorgensen K. Modern insulin therapy in children and adolescents. Acta Paediatrica 1999; 88(427): 25-30. [http://dx.doi.org/10.1111/j.1651-2227.1999.tb14336.x]

[13] Meltzer LJ, Johnson SB, Prine JM, Banks RA, Desrosiers PM, Silverstein JH. Disordered eating, body mass, and glycemic control in adolescents with type 1 diabetes. Diabetes Care 2001; 24(4): 678-82. [http://dx.doi.org/10.2337/diacare.24.4.678] [PMID: 11315830] 
[14] Kitzler TM, Bachar M, Skrabal F, Kotanko P. Evaluation of treatment adherence in type 1 diabetes: a novel approach. Eur J Clin Invest 2007; 37(3): 207-13. [http://dx.doi.org/10.1111/j.1365-2362.2007.01771.x] [PMID: 17359488]

[15] Parga M, Llorente R. Discriminant analysis of treatment adherence in insulin-dependent diabetes mellitus. Psychol Spain 2005; 9: 41-8.

[16] Kaufman FR, Halvorson M, Carpenter S. Association between diabetes control and visits to a multidisciplinary pediatric diabetes clinic. Pediatrics 1999; 103(5 Pt 1): 948-51.

[http://dx.doi.org/10.1542/peds.103.5.948] [PMID: 10224170]

[17] Svoren BM, Volkening LK, Butler DA, Moreland EC, Anderson BJ, Laffel LM. Temporal trends in the treatment of pediatric type 1 diabetes and impact on acute outcomes. J Pediatr 2007; 150(3): 279-85. [http://dx.doi.org/10.1016/j.jpeds.2006.12.009] [PMID: 17307546]

[18] Schiffrin A, Belmonte M. Multiple daily self-glucose monitoring: its essential role in long-term glucose control in insulin-dependent diabetic patients treated with pump and multiple subcutaneous injections. Diabetes Care 1982; 5(5): 479-84. [http://dx.doi.org/10.2337/diacare.5.5.479] [PMID: 6765224]

[19] Karter AJ, Ackerson LM, Darbinian JA, et al. Self-monitoring of blood glucose levels and glycemic control: the Northern California Kaiser Permanente Diabetes registry. Am J Med 2001; 111(1): 1-9. [http://dx.doi.org/10.1016/S0002-9343(01)00742-2] [PMID: 11448654]

[20] Kordonouri O, Lauterborn R, Deiss D. Lipohypertrophy in young patients with type 1 diabetes. Diabetes Care 2002; $25(3)$ : 634. [http://dx.doi.org/10.2337/diacare.25.3.634] [PMID: 11874968]

[21] Chowdhury TA, Escudier V. Poor glycaemic control caused by insulin induced lipohypertrophy. BMJ 2003; 327(7411): 383-4. [http://dx.doi.org/10.1136/bmj.327.7411.383] [PMID: 12919996]

[22] Alemzadeh R, Loppnow C, Parton E, Kirby M. Glucose sensor evaluation of glycemic instability in pediatric type 1 diabetes mellitus. Diabetes Technol Ther 2003; 5(2): 167-73.

[http://dx.doi.org/10.1089/152091503321827821] [PMID: 12871606]

[23] Fasy E, Umpierrez G. Case study: Celiac disease: an important comorbidity associated with type 1 diabetes. Clin Diabetes 2008 ; 26 : 85-7. [http://dx.doi.org/10.2337/diaclin.26.2.85]

[24] Lazzarotto F, Basso D, Plebani M, Moscon A, Zanchetta R, Betterle C. Celiac disease and type 1 diabetes. Diabetes Care 2003; 26(1): 248-9. [http://dx.doi.org/10.2337/diacare.26.1.248] [PMID: 12502694]

[25] Bouguerra R, Ben Salem L, Chaâbouni H, et al. Celiac disease in adult patients with type 1 diabetes mellitus in Tunisia. Diabetes Metab 2005; 31(1): 83-6.

[http://dx.doi.org/10.1016/S1262-3636(07)70171-4] [PMID: 15803118]

[26] Moayeri H, Bahremand S. Prevalence of celiac disease in children and adolescents with type 1 diabetes mellitus. Med J Islam Repub Iran 2004; 18: 39-43.

[27] Andreelli F, Plotton I, Riou JP, Thivolet C. Diabetic instability and celiac disease. A frequent association to keep in mind. Diabetes Care 1998; 21(12): 2192-3. [http://dx.doi.org/10.2337/diacare.21.12.2192] [PMID: 9839118]

[28] Amin R, Murphy N, Edge J, Ahmed ML, Acerini CL, Dunger DB. A longitudinal study of the effects of a gluten-free diet on glycemic control and weight gain in subjects with type 1 diabetes and celiac disease. Diabetes Care 2002; 25(7): 1117-22. [http://dx.doi.org/10.2337/diacare.25.7.1117] [PMID: 12087007]

(C) Yazidi et al.; Licensee Bentham Open

This is an open access article licensed under the terms of the Creative Commons Attribution-Non-Commercial 4.0 International Public License (CC BY-NC 4.0) (https://creativecommons.org/licenses/by-nc/4.0/legalcode), which permits unrestricted, non-commercial use, distribution and reproduction in any medium, provided the work is properly cited. 